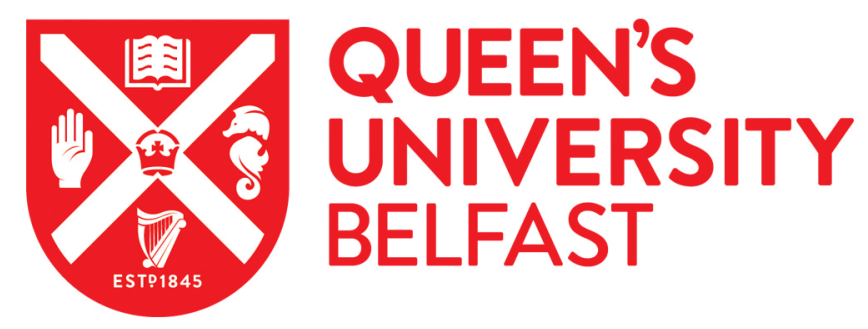

\title{
The Development of TASTER, a Cognitive Training Game Using Human-Centered Design, Tailored for Children with Global and Specific Cognitive Impairments
}

Robb, N., Waller, A., \& Woodcock, K. (2015). The Development of TASTER, a Cognitive Training Game Using Human-Centered Design, Tailored for Children with Global and Specific Cognitive Impairments. In Proceedings of 2015 7th International Conference on Games and Virtual Worlds for Serious Applications (VS-Games) Institute of Electrical and Electronics Engineers Inc.. https://doi.org/10.1109/VS-GAMES.2015.7295788

\section{Published in:}

Proceedings of 2015 7th International Conference on Games and Virtual Worlds for Serious Applications (VSGames)

\section{Document Version:}

Peer reviewed version

Queen's University Belfast - Research Portal:

Link to publication record in Queen's University Belfast Research Portal

\begin{abstract}
Publisher rights
(C) 2015 IEEE. Personal use of this material is permitted. Permission from IEEE must be obtained for all other uses, in any current or future media, including reprinting/republishing this material for advertising or promotional purposes, creating new collective works, for resale or redistribution to servers or lists, or reuse of any copyrighted component of this work in other works.
\end{abstract}

\section{General rights}

Copyright for the publications made accessible via the Queen's University Belfast Research Portal is retained by the author(s) and / or other copyright owners and it is a condition of accessing these publications that users recognise and abide by the legal requirements associated with these rights.

Take down policy

The Research Portal is Queen's institutional repository that provides access to Queen's research output. Every effort has been made to ensure that content in the Research Portal does not infringe any person's rights, or applicable UK laws. If you discover content in the Research Portal that you believe breaches copyright or violates any law, please contact openaccess@qub.ac.uk. 


\title{
The Development of TASTER, a Cognitive Training Game Using Human-Centered Design, Tailored for Children with Global and Specific Cognitive Impairments
}

\author{
Nigel Robb ${ }^{1}$, Annalu Waller ${ }^{2}$, Kate A. Woodcock ${ }^{1}$ \\ ${ }^{1}$ School of Psychology \\ Queen's University Belfast \\ Belfast, UK \\ ${ }^{2}$ School of Computing \\ University of Dundee \\ Dundee, UK
}

\begin{abstract}
Children with Prader-Willi syndrome often exhibit challenging behavior in response to changes to routine. This phenomenon has been linked to a deficit in task switching ability which has been observed in children with the syndrome. TASTER is a cognitive training game which is being designed with input from a group of children with Prader-Willi syndrome, which aims to train task switching ability and thus reduce associated challenging behavior.
\end{abstract}

Keywords-human-centered design; serious games; PraderWilli syndrome; cognitive training; task switching

\section{INTRODUCTION}

Prader-Willi syndrome (PWS) is a rare genetic disorder usually associated with mild to moderate intellectual disability (ID) and resistance to change [1]. In particular, temper outbursts due to changes to plans or routines have been linked to a deficit in task switching ability in individuals with PWS [2], [3], [4]. Video games have produced gains in specific cognitive processes in several typical and atypical populations [5]. Additionally, research in cognitive neuroscience has demonstrated a link between playing action video games (AVGs) and an increase in task switching ability [6], [7].

\section{SPECIFIC APPLICATION}

We are developing TASTER, a video game designed to train task switching in children with PWS. By increasing task switching ability, we aim to decrease occurrences of temper outbursts associated with changes to plans or routines. As such, our game aims to have a positive effect on clinically-significant behavior by targeting a specific cognitive impairment that has been linked to the behavior.

\section{DESIGN AND DEVELOPMENT}

It is essential that the game produced is tailored to the preferences and capabilities of children with PWS, who - due to cognitive impairments and behavioral traits associated with the syndrome - may not be capable of playing, or motivated to play, typical entertainment games. It is also important to fully utilize the insights afforded by the aforementioned research on

The authors would like to thank the Foundation for Prader-Willi Research, for sponsoring the research. the cognitive benefits of AVGs. Therefore, our iterative development process incorporates both human-centered design in the form of observational studies, and a domain analysis of AVGs. Observational studies took place before any design decisions had been made (using existing entertainment games), and will continue throughout development (using prototypes). The children can therefore be considered design informants [8].

\section{A. Observational studies}

1) Participants and procedure: Seven children with PWS (age 7 - 15; six female, one male) played a selection of existing games, in order to observe how they interacted with existing technology [8]. Children played the games during sessions lasting at least 30 minutes, with multiple sessions taking place over two weeks. To overcome difficulties faced by children with ID when expressing their preferences [9], most questions were presented as a forced choice between two alternatives, with images used where possible.

2) Results: Six children preferred playing games on a handheld tablet. Children preferred games in which they were tasked with collecting items (e.g. coins) (Table I), and preferred controlling games using simple touch gestures (Table II). Scores were calculated from responses to forcedchoice questions comparing features; scores show the number of times a feature was preferred as a proportion of the total number of times the feature was considered.

TABLE I. OVERALL GAMEPLAY PREFERENCES

\begin{tabular}{|l|l|l|l|l|}
\hline \multirow{2}{*}{} & \multicolumn{4}{|c|}{ Gameplay feature } \\
\cline { 2 - 5 } & $\begin{array}{c}\text { Collecting } \\
\text { items }\end{array}$ & $\begin{array}{c}\text { Controlling } \\
\text { characters }\end{array}$ & $\begin{array}{c}\text { Shape-based } \\
\text { puzzles }\end{array}$ & $\begin{array}{c}\text { Building and } \\
\text { creating }\end{array}$ \\
\hline Score & 0.64 & 0.57 & 0.48 & 0.36 \\
\hline
\end{tabular}

TABLE II. OVERALL PREFERENCES FOR CONTROL SYSTEM

\begin{tabular}{|l|l|l|l|l|l|}
\hline \multirow{2}{*}{} & \multicolumn{5}{|c|}{ Control system } \\
\cline { 2 - 6 } & $\begin{array}{c}\text { Touching } \\
\text { screen }\end{array}$ & Keyboard & $\begin{array}{c}\text { On-screen } \\
\text { buttons }\end{array}$ & Mouse & $\begin{array}{c}\text { Moving the } \\
\text { tablet }\end{array}$ \\
\hline Score & 0.79 & 0.71 & 0.48 & 0.29 & 0.14 \\
\hline
\end{tabular}




\section{B. Domain analysis}

While AVGs show benefits in task switching ability, typical AVGs are not suitable for children with ID due to the complexity of the gameplay, the use of themes unsuitable for young children (e.g. violence) and the complexity of the control systems. The domain analysis aimed to identify features of AVGs that could be incorporated into a game suitable for children with ID, for example:

- Monitoring on-screen information during gameplay.

- Adapting goals due to unforeseen circumstances.

- The presence of distracting stimuli which must be filtered and ignored.

\section{Conceptual design}

A game was designed in which players must control a character to collect items (the preferred gameplay identified during observational studies). The items are creatures which can be identified in terms of their color (red or blue) or shape (cuboid or pyramid) (Fig. 1). Players must collect only one kind of creature at a time, with the current target specified as either a shape or a color; by changing how the target is specified, players are forced to switch how they conceptualize the creatures (the task switch). The game incorporates the three features of AVGs mentioned above: information panels and messages are displayed on screen; large rocks, which must be avoided, appear at random intervals in the player's path; and distracting stimuli occur in the form of sound effects, particle effects, and a screen shake effect. The player's character is controlled by touching the screen at the location which they wish to move to, in line with the preference for simple touch controls expressed by children in observational studies.

\section{Prototype}

A prototype game was developed for handheld tablets, the preferred distribution platform of the children who took part in the observational studies.

\section{E. Playtesting}

1) Participants and procedure: To date, five children with PWS (age 7 - 15; three female, two male) have tested the game. Children played the game for at least 30 minutes, and answered questions designed to gauge the usability of the prototype, their motivation to play it and their level of comprehension of the gameplay.

2) Results: Initial results show that players achieve a high level of satisfaction from the game, are motivated to play it, and find the interface and gameplay easy to understand.

\section{CONCLUSION}

Children with ID can play the role of design informants [8] in the design of cognitive training games. Furthermore, the design of serious games in general can benefit from analysis of entertainment games, to identify features that might contribute to the effectiveness of the serious game.
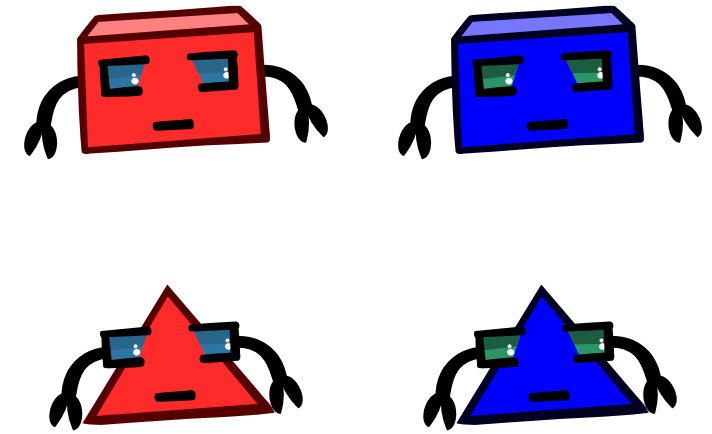

Fig. 1. The creatures which the player must collect. Each creature can be identified in terms of its color or its shape.

\section{FUTURE WORK}

\section{A. Development}

The prototype will be refined in an iterative process, incorporating feedback from playtesting sessions, using further observational studies of children with PWS as they interact with the prototype game.

\section{B. Validation}

The final game will be evaluated for its effect on task switching ability in a placebo controlled, cross-over design over ten weeks, with participants' task switching ability assessed - using a custom battery of task switching assessments tailored for children with ID - at baseline, after five weeks, and after ten weeks.

\section{REFERENCES}

[1] J. Whittington, 'Population prevalence and estimated birth incidence and mortality rate for people with Prader-Willi syndrome in one UK Health Region', J. of Medical Genetics, vol. 38, no. 11, pp. 792-798, 2001.

[2] K. A. Woodcock, C. Oliver and G. Humphreys, 'Task-switching deficits and repetitive behaviour in genetic neurodevelopmental disorders: Data from children with Prader-Willi syndrome chromosome 15 q11-q13 deletion and boys with Fragile $\mathrm{X}$ syndrome', Cognitive Neuropsychology, vol. 26, no. 2, pp. 172-194, 2009.

[3] K. A. Woodcock, G. Humphreys, C. Oliver and P. Hansen, 'Neural correlates of task switching in paternal 15q11-q13 deletion Prader-Willi syndrome', Brain Research, vol. 1363, pp. 128-142, 2010.

[4] K. A. Woodcock, C. Oliver and G. Humphreys, 'The relationship between specific cognitive impairment and behaviour in Prader-Willi syndrome', J. of Intellectual Disability Research, vol. 55, no. 2, pp. 152$171,2011$.

[5] T. Klingberg, H. Forssberg, and H. Westerberg, 'Training of working memory in children with ADHD', J. of Clinical and Experimental Neuropsychology, vol. 24, no. 6, pp. 781-791, 2002.

[6] C. S. Green, M. Sugarman, K. Medford, E. Klobusicky and D. Bavelier, 'The effect of action video game experience on task-switching', Comput. in Human Behavior, vol. 28, no. 3, pp. 984-994, 2012.

[7] C. S. Green and D. Bavelier, 'Learning, Attentional Control, and Action Video Games', Current Biology, vol. 22, no. 6, pp. R197-R206, 2012.

[8] A. Druin, 'The role of children in the design of new technology', Behaviour \& Inform. Technology, vol. 21, no. 1, pp. 1-25, 2002.

[9] H. Prosser and J. Bromley, 'Interviewing people with intellectual disabilities', in Clinical Psychology and People with Intellectual Disabilities, 2nd ed., E. Emerson, K. Dickson, R. Gone, C. Hatton, J. Bromley and A. Caine, Eds. New York: John Wiley \& Sons, 2012, pp. 107-120. 